\title{
DESTERCEIRIZAÇÃO COMO ESTRATÉGIA DE NEGÓCIO: UM ESTUDO DE CASO
}

Sara da Costa Fernandes ${ }^{1 *}$, Larissa Juliana Patrocínio da Silva², Jamille Araújo Paixão ${ }^{3}$, Vagner Rosalem ${ }^{4}$

${ }^{*}$ Autor para correspondência

1. Mestranda em Gestão Organizacional, Universidade Federal de Goiás (UFG), Campus Catalão. Catalão - GO, Brasil. (sara.scf1@gmail.com)

2. Mestranda em Gestão Organizacional, Universidade Federal de Goiás (UFG), Campus Catalão. Catalão - GO, Brasil.

3. Mestranda em Gestão Organizacional, Universidade Federal de Goiás (UFG), Campus Catalão. Catalão - GO, Brasil.

4. Doutor em Administração de Empresas EAESP/FGV e Docente na Universidade Federal de Goiás (UFG), Campus Catalão. Catalão - GO, Brasil.

Recebido em: 03/10/2016 - Aprovado em: 21/11/2016 - Publicado em: 05/12/2016 DOI: 10.18677/EnciBio_2016B_185

\begin{abstract}
RESUMO
Em decorrência da escassez de recursos, competitividade e a atual conjuntura econômica brasileira, as organizações buscam estratégias racionalizadoras que gerem melhores resultados com menores custos garantindo assim sua sobrevivência. Com o processo de desindustrialização e escassez econômica as organizações como as do setor automobilístico adotam estratégias de primarização ou integração (desterceirização) de processos anteriormente terceirizados. Assim, ao considerar a configuração econômica atual e a indústria automotiva brasileira, este estudo possui o objetivo de identificar os principais fatores que viabilizaram a integração (insource) de processo de montagem e balanceamento de pneus vinculando-os como um dos processos primários da montadora. Foi realizado um estudo de caso com uma montadora de veículos na região do Sudeste de Goiás em que através da análise documental identificou-se a viabilidade para a integração das atividades em questão. Os principais fatores motivadores para esta estratégia de negócio, foram a otimização e redução de custos totais de produção.
\end{abstract}

PALAVRAS-CHAVE: desterceirização; estratégias; montadora de veículos.

\section{INSOURCING AS A BUSINESS STRATEGY}

\begin{abstract}
Due to the scarcity of resources, competitiveness and the current Brazilian economic situation, organizations seek to rationalize strategies that generate better results with lower costs to ensure their survival. With the process of de-industrialization and economic scarcity organizations such as the automotive industry adopt insourcing strategies or integration previously outsourced processes. So, when considering the current economic setting and the Brazilian automotive industry, this study has the objective to identify the main factors that became possible the integration (insource) assembly process and tire balancing linking them as one of the primary processes of
\end{abstract}


the company. It was made a case study with a vehicle assembler in the region of Southeast Goiás that through document analysis identified the feasibility of the integration of the activities related. The main motivating factors for this business strategy were the optimization and reduction of total production costs.

KEYWORDS: strategies; integration; vehicle assembly.

\section{INTRODUÇÃO}

A crescente competição globalizada nos últimos anos direciona as organizações a um discurso único sobre a necessidade de se tornarem mais competitivas. A escassez de recursos e o aumento de competição exigem das organizações a adoção de estratégias racionalizadoras que gerem melhores resultados para sobrevivência. Uma das ferramentas diante destes desafios está a terceirização que "foi largamente usada como sinônimo de maior agilidade no processo produtivo". As vantagens da terceirização dependem de uma combinação de fatores, como cenário econômico, eficiência do processo de fornecimento, grau de confiança no fornecedor e necessidades estratégicas organizacionais (SARAIVA \& VIANNA, 2009).

Muitos processos de terceirização são ineficientes em decorrência de diversos problemas, muitos destes associados à conjuntura econômica e consequente necessidade de redução de custos nas organizações. Nos dias atuais isto ocorre no Brasil, que passa por um momento de instabilidade financeira conforme argumentam OREIRO \& MARCONI (2014) o país passa por um processo de desindustrialização, que "é definido como um processo de natureza estrutural no qual a participação da indústria no emprego e no PIB se reduz de forma consistente ao longo do tempo". Ainda para estes autores a indústria brasileira passa por um processo de necessidade de re-primarização (desterceirização) de suas atividades.

Neste cenário, a indústria brasileira como a automobilística, em resposta a recessão econômica e a recente crise, passa por uma transformação estratégica, especialmente no diz respeito à desterceirização ou integração de algumas atividades (DRAUZ, 2013). Baseado no estudo de CALIXTRE et al. (2014), identifica-se que as circunstâncias atuais são outras e a competitividade e necessidade de crescimento são urgentes, visto os sinais de perda de participação da indústria automotiva no PIB. As organizações deste setor, no entanto devem garantir a integração de suas atividades e com outros setores da economia para que tenham chances de sobreviver.

A desterceirização pode ser também chamada de primarização, verticalização ou integração vertical, insourcing, reverse outsourcing ou re-insourcing (DRAUZ, 2013), e é um processo caracterizado pela reversão da terceirização consistindo em retornar as atividades que haviam sido terceirizadas para os processos internos (MAGALHÃES et al., 2009). Considerando as transformações e estagnação da atual economia brasileira,

Este estudo possui o objetivo principal de identificar os principais fatores que viabilizaram a integração (insource) do processo de montagem e balanceamento de pneus vinculando-os como um dos processos primários de uma montadora de veículos. Visando atingir o objetivo geral, este estudo propõe como objetivos específicos descrever os conceitos e interesses estratégicos referente a processos de desterceirização e a importância da sobrevivência do setor automotivo para cenário econômico brasileiro atual. Além disto, procura-se identificar os aspectos 
indicativos de redução de custos e consequente maior retorno para a organização estudada.

\section{MATERIAL E MÉTODOS}

Para atingir os objetivos propostos na presente pesquisa, foi realizado um estudo de caso de natureza qualitativa em uma montadora de veículos do Sudoeste Goiano, especificamente quanto às operações de montagem e balanceamento de rodas e pneus.

O estudo de caso foi realizado em Agosto de 2016. Com caráter exploratório e natureza descritiva, buscou-se entender qual ou quais os fatores que viabilizaram a desterceirização/insource do processo produtivo de montagem e balanceamento de rodas e pneus da montadora. A investigação permitiu formular associações em relação ao assunto e as informações consideradas importantes para responder ao problema de pesquisa e alcançar os objetivos propostos.

A coleta de dados foi realizada mediante análise documental, de relatórios contendo o escopo do projeto e os estudos de viabilidade de desterceirização, em relação aos custos de tal processo. Os documentos são da própria organização que é a unidade de análise deste estudo, e são do período de Fevereiro e Março de 2016. Assim, foi apresentado através da documentação, a fonte de evidências e informações possibilitando identificar e analisar o estudo de viabilidade para deterceirização como estratégia de negócio referente ao processo de montagem e balanceamento de rodas e pneus em uma organização do setor automotivo.

A análise de dados foi realizada por meio da análise de conteúdo, conforme os passos propostos por BARDIN (2009). Os documentos foram solicitados à organização, e os dados de interesse (referente à viabilidade financeira) foram agrupados e consolidados. Posteriormente, foram interpretados de acordo com os objetivos propostos nesta pesquisa.

\section{RESULTADOS E DISCUSSÃO}

A desterceirização pode ser também chamada de primarização, verticalização ou integração vertical, insourcing, reverse outsourcing ou re-insourcing (DRAUZ, 2013), e é um processo caracterizado pela reversão da terceirização consistindo em retornar as atividades que haviam sido terceirizadas para os processos internos (MAGALHÃES et al., 2009).

Conforme afirmam, PORTER (2005) e MONTELLA (2006), a desterceirização ou insource pode ser definida por integração vertical, pois está originalmente interligado com os custos de transação, através da transferência de insumos vinculando a uma produção primária. Os processos de produção, distribuição, vendas e outros processos possam ficar nas fronteiras de uma mesma empresa e sob um comando decisório.

$\mathrm{Na}$ dinâmica que envolve o mercado empresarial atual, a desterceirização ou integração vertical direcionam as organizações a amplitudes e equilíbrio entre todas as etapas de suas operações. Estes fatores são determinantes para que as organizações definam estrategicamente quais operações voltarão a ser realizadas internamente e se isto é viável, considerando custos e recursos organizacionais (SALLES \& OLIVEIRA, 2011).

No setor automotivo, algumas mudanças nos contextos político e econômico brasileiro direcionam as organizações do setor automotivo a definirem novas 
estratégias de posicionamento e sobrevivência. O momento ruim e a competitividade entre as organizações do setor as levam a definirem medidas de "redução dos custos, ampliação da escala e desenvolvimento da sua cadeia, indo além da gestão interna da produção" (STOICOV \& FERRONI, 2012).

Neste contexto, para realizar esta pesquisa, foi estudada uma montadora de veículos no sudeste Goiano e o processo de integração de atividades de montagem e balanceamento de rodas e pneus. A montadora não foi identificada nesta pesquisa, mas será utilizado o projeto/estudo de viabilidade para a integração de atividades, identificando que esta estratégia é viável considerando o atual cenário econômico com poucas vendas de veículos.

Em 2016, com a queda de vendas de veículos automotores no Brasil, com a possibilidade de maiores ganhos ou menores investimentos e por questões de planejamento, suprimento, produção, logística e tecnologia a montadora identificou a necessidade de uma estratégia de integração/desterceirização do processo de montagem e balanceamento de rodas e pneus anteriormente realizado por um fornecedor local. O projeto/estudo de viabilidade se iniciou em 2016 e passou por fase de negociações e planejamento de fluxos, lay out, instalação, estoques, logística e fiscal.

Neste estudo, buscou-se analisar os fatores motivadores para a estratégia de integração da atividade. Foi disponibilizada pela Engenharia de Manufatura da organização estudada, a documentação de projeto de viabilidade e for am identificadas as vantagens da integração das atividades da montadora de veículos do Sudeste de Goiás. As áreas de conhecimento do projeto de Insource, como foi chamado, que serão apresentados são: escopo, demonstração do custo do projeto e a viabilidade final.

A Figura 1 apresenta o escopo do projeto de Insource do fornecedor de montagem e balanceamento de pneus que teve como principal objetivo a integração das atividades a serem realizadas pela montadora passando assim por um processo de desterceirização. As operações analisadas e consideradas foram os processos de compras de pneus comprados pela própria montadora, mas entregues direto na planta do fornecedor; processo de recebimento com os caminhões utilizados próprios do fornecedor; expedição como a movimentação de pallets e bandejas; a montagem de roda e pneu que após esta operação seguiam as seguintes etapas: enchimento, calibração e balanceamento. 
OBJETIVO / ESCOPO DO PROJETO:

Transferir as operações de montagem e balanceamento de rodas e pneus da empresa terceirizada para a montadora de veículos

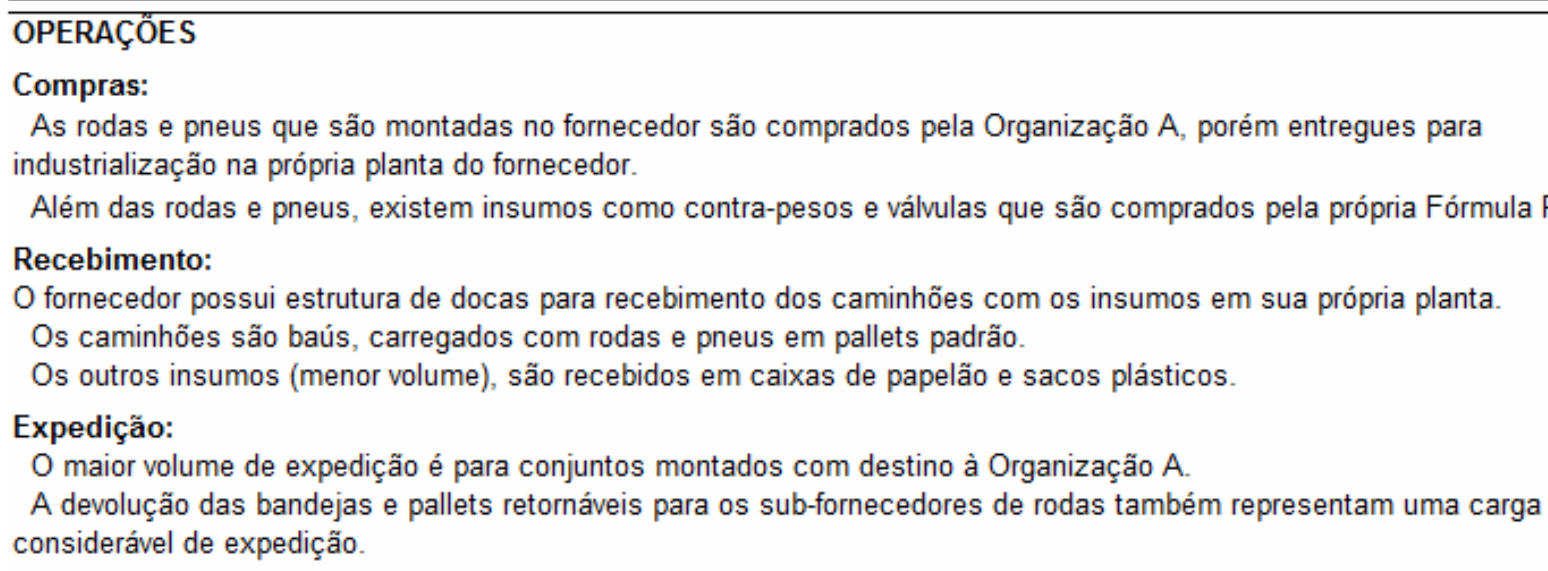

\section{Montagem de Roda/Pneu:}

As montagem das rodas e pneus são realizadas em 3 linhas distintas, seguindo as seguintes etapas:

- Montagem das rodas e pneus.

- Enchimento.

- Calibração.

- Balanceamento.

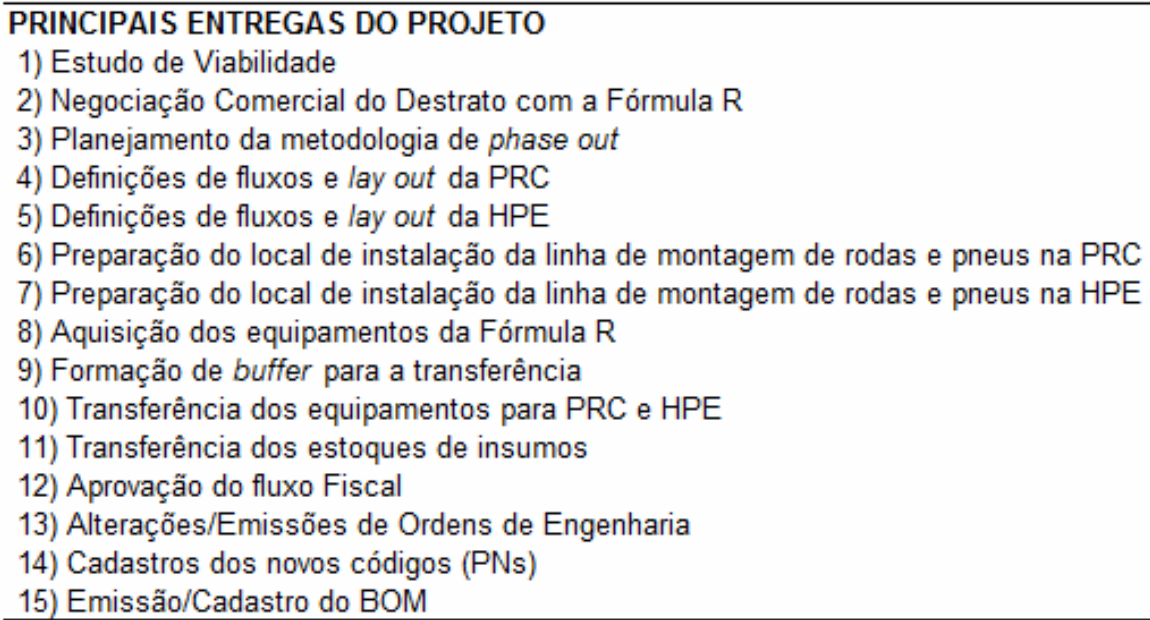

FIGURA 1 - Escopo Projeto Insource

FONTE: Documentação da Organização pesquisada (2016)

Conforme mostra a Figura 1, as principais entregas do projeto foram: o estudo de viabilidade (que está sendo apresentada neste trabalho); negociação comercial do destrato com o fornecedor; planejamento; preparação logística; transferência de equipamentos; estoques e insumos; alteração de fluxo fiscal e novas emissões de ordem de engenharia. Após identificar a viabilidade do projeto de integração das atividades, todas estas entregas foram planejadas e executadas pela área de Engenharia de Manufatura juntamente com Logística.

No estudo de caso apresentado, a integração das atividades de montagem e balanceamento de rodas e pneus foi integral e por isto foi analisado a estimativa orçamentária considerando dois cenários : atividade realizada no fornecedor e atividade desterceirizada e integrada na montadora, conforme apresentado na Figura 2. 


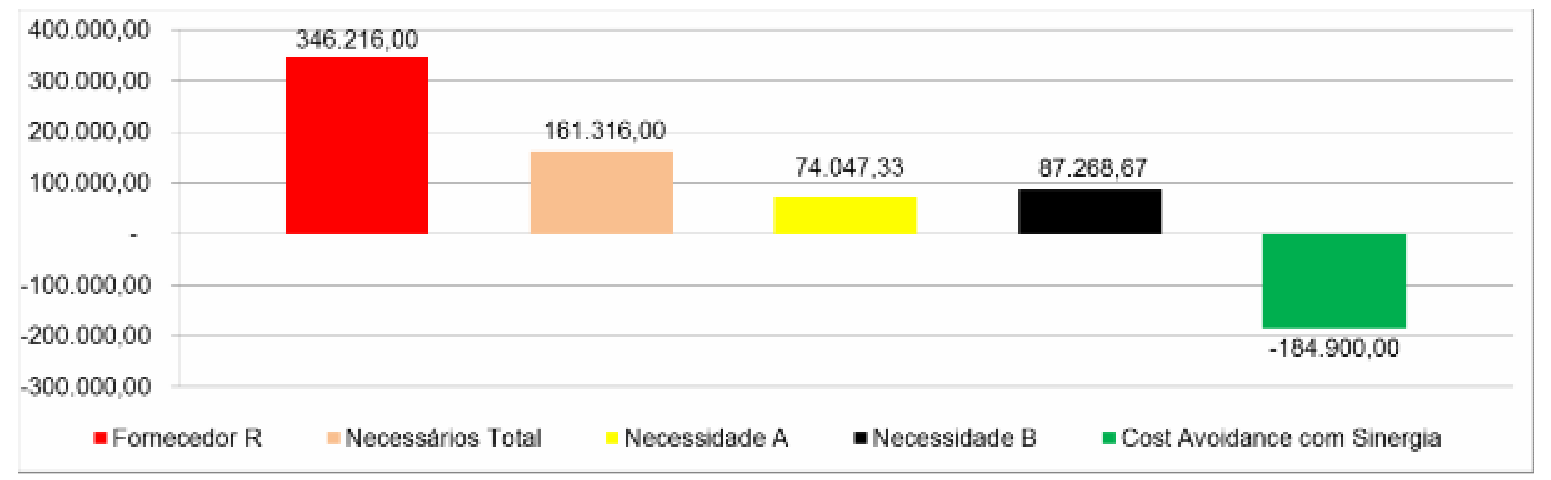

FIGURA 2 - Custos com Projeto

FONTE: Documentação da Organização pesquisada (2016)

Com a integração da atividade a montadora evitou um custo mensal (Cost Avoidance) no valor de $\mathrm{R} \$ 184.900,00$ demonstrando assim uma economia e viabilidade financeira para a montadora. Com a integração de processos operacionais e menores custos, conduzem a maiores lucros e criação de valor aos proprietários da organização. Neste sentido, os resultados do projeto de viabilidade orçamentária sinalizaram a redução de custos e despesas e gerou sinergias econômicas e operacionais.

Alinhado a isto, SARAIVA \& VIANNA (2009) afirmam que, ao identificar os efeitos dos custos anuais com fornecedores, as organizações voltam a integrar o processo produtivo, desterceirizando algumas atividades. A decisão de terceirizar ou primarizar vai depender do cenário econômico e das estratégias de cada organização

A Figura 3 apresenta o faturamento do Fornecedor em 2015, calculado em $\mathrm{R} \$ 2.390 .103,00$ e uma projeção para o ano de $2016 \mathrm{em} \mathrm{R} \$ 1.782 .376,00$. Ao realizar a análise de viabilidade, o estudo considerou os principais custos com a integração da atividade como: mão de obra; depreciação; expediente e insumos de produção; chegando a uma projeção após Insource das atividades em $\mathrm{R} \$$ 1.236.251,00, ou seja, uma variação e economia de $R \$ 546.125,00$ no ano.

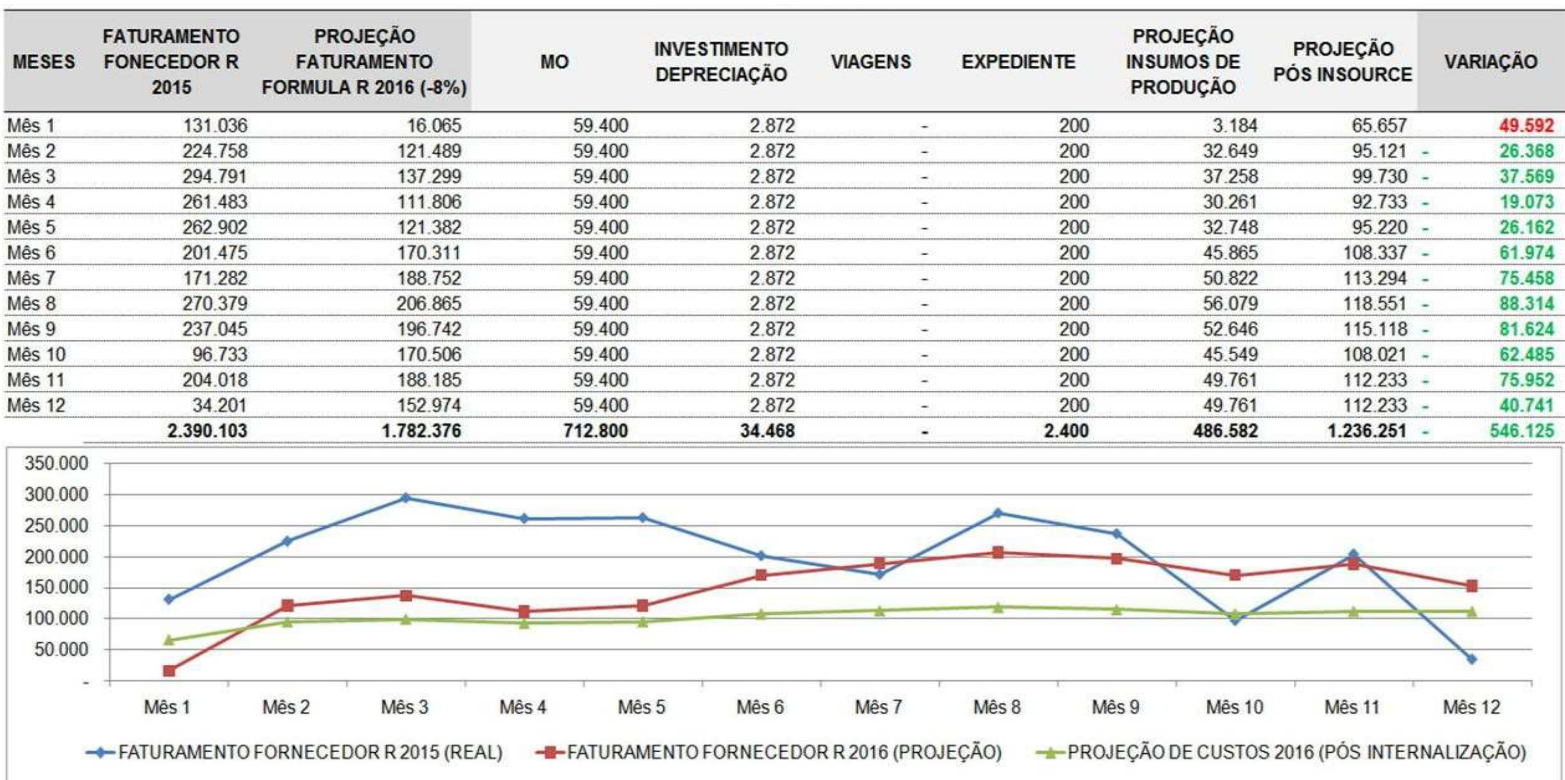

FIGURA 3 - Viabilidade do Insource

FONTE: Documentação da Organização pesquisa (2016) 
Através do projeto/estudo de viabilidade feito pela montadora, identificou-se que a desterceirização das atividades de montagem e balanceamento de rodas e pneus apresenta o retorno estimado aos proprietários. Neste contexto, a estratégia de integração dos processos de diferentes elos da cadeia produtiva direciona a eficiência operacional e de custos, além da racionalização de recursos operacionais gerando retorno do investimento aplicado.

\section{CONCLUSÃO}

Como forma de oportunidade de crescimento, o setor automotivo adota estratégias como a desterceirização que são importantes, principalmente ao considerar a instabilidade financeira e econômica no Brasil nos dias atuais. Com este cenário, com o acirramento da concorrência e na busca da maximização de lucros, as indústrias automotivas adotam estratégias de integração de atividades em sua planta como forma de sobreviverem no mercado e se desenvolverem.

$\mathrm{Na}$ busca de redução de custos e racionalidade estratégica uma organização do setor automotivo do Sudeste Goiano identificou a necessidade de desterceirização de um processo de montagem e balanceamento de rodas e pneus, anteriormente realizado por um fornecedor local. Os principais fatores motivadores para esta estratégia de negócio foi a otimização e redução de custos totais de produção. A projeção pós insource das atividades apresenta uma economia no valor total de $R \$ 546.125,00$ no ano de 2016. Um valor representativo considerando o momento instável da economia brasileira.

Assim, a apropriação do lucro e a integração de atividades de diferentes elos da cadeia produtiva direcionam as organizações à eficiência operacional e econômica. As organizações devem montar estratégias e planejarem investimentos que gerem retorno aos proprietários e consequente redução de custos. A busca constante de bons resultados operacionais e financeiros é um diferencial para sobrevivência e competitividade da indústria brasileira.

\section{AGRADECIMENTOS}

Os autores agradecem à empresa montadora de veículos pela colaboração com o estudo de caso. Também, à Fundação de Amparo à Pesquisa do Estado de Goiás - FAPEG, pela contribuição para a realização da pesquisa.

\section{REFERÊNCIAS}

BARDIN, L. Análise de Conteúdo. 5ed. Lisboa: Edições 70, 2009.

CAliXtRe, A. B.; BIANCARELLI, A. M.; CINTRA, M. A. M. Presente e futuro do desenvolvimento brasileiro. Brasília: 2014.

DRAUZ, R. Re-insourcing as a manufacturing-strategic option during a crisis: cases from the automobile industry. Journal of Business Research, v. 67, p. 346-353, 2013. Disponível em: http://isiarticles.com/bundles/Article/pre/pdf/43249.pdf. DOI: 10.1016/j.jbusres.2013.01.004.

MAGALHÃES, Y. T.; SOUZA, M. C. O.; ANDRADE, F. O. Da terceirização à primarização: um estudo em uma mineradora de grande porte. In: Simpósio De Engenharia de Produção. Anais... Bauru: UNESP, 2009.

MONTELLA, M. Economia, administração contemporânea e engenharia de 
produção: um estudo de firma. Rio de Janeiro, Qualitymark, 2006.

OREIRO, J. L.; MARCONI, N. Teses equivocadas no debate sobre desindustrialização e perda de competitividade da indústria brasileira. Revista NECAT. Ano 3, nำ Jan/Jun 2014.

PORTER, M. E. (2005) Estratégia competitiva: técnicas para análise de indústrias e da concorrência ( $2^{\mathrm{a}}$ ed.). Rio de Janeiro: Campus/Elsevier.

SALLES, M, B.; OLIVEIRA, S. B. Delineando a Estratégia de Integração Vertical em um Contexto de Expansão dos Serviços de Concretagem: Uma Pesquisa Exploratória. In: XXXV Encontro da ANPAD. Anais... Rio de Janeiro, 2011.

SARAIVA, L. A. S.; VIANNA, S. O. F. Representações sociais do trabalho em um quadro de expectativa da primarização: um estudo em uma instituição de ensino superior. Revista Economia \& Gestão, V.9. n. 20. 2009. Disponível em: $<$ http://periodicos.pucminas.br/index.php/economiaegestao/article/view/P.19846606. 2009v9n20p89 >. DOI 10.5752/P.1984-6606.2009V9N20P89.

STOICOV, C.; FERRONI, G. Sustentabilidade no Setor Automotivo. Série de Estudo Setoriais Uniethos. São Paulo, 2012. 52 p. 